\title{
Biodegradation Processes on the Facades of Residential Housing from the Point of View of Energy Savings
}

\author{
Darja Kubečková*, Magdaléna Vrbová \\ VSB-TU Ostrava, Faculty of Civil Engineering, Ostrava, 70800, Czech Republic
}

Received March 9, 2021; Revised April 15, 2021; Accepted May 23, 2021

\section{Cite This Paper in the following Citation Styles}

(a): [1] Darja Kubečková, Magdaléna Vrbová, "Biodegradation Processes on the Facades of Residential Housing from the Point of View of Energy Savings," Civil Engineering and Architecture, Vol. 9, No. 3, pp. 899 - 908, 2021. DOI: 10.13189/cea.2021.090332.

(b): Darja Kubečková, Magdaléna Vrbová (2021). Biodegradation Processes on the Facades of Residential Housing from the Point of View of Energy Savings. Civil Engineering and Architecture, 9(3), 899 - 908. DOI: 10.13189/cea.2021.090332.

Copyright@2021 by authors, all rights reserved. Authors agree that this article remains permanently open access under the terms of the Creative Commons Attribution License 4.0 International License

\begin{abstract}
After 2000, 2010, energy and heat savings became a key concern of the European Parliament and the Council of the European Union. The result of these efforts and activities was, in particular, the introduction of the Energy Performance of Buildings Directive (EPBD I., EPBD II., include EPBD II. recast), into the legal ambience of the EU Member States. The resulting requirements are mainly reflected in the areas of energy decrees and normative regulations and place high demands on the gradual reduction of energy consumption and overall sustainability. The new thermal-technical and energy legislation and ever-stricter criteria of the European Union require among other things that measures taken towards overall improvement of building performance should include better quality thermal insulation of building envelopes of both, new and refurbished buildings. However, one has to evaluate real impact of improved thermal insulation and energy saving parameters within the context of the overall structural and environmental design of buildings by also taking into account the ramifications of such improvements to building structures. On the one hand, there is a qualitative energy improvement; on the other hand, we encounter new manifestations of defects and failures in the form of biodegradation of facades. The aim of the paper is to present a case study based on monitoring of prefabricated apartment buildings, laboratory analysis of biodegradation microorganisms and model calculations, and to explore how increasing the thickness of thermal insulation can negatively affect the condition of the building facade and how they can start biodegradation processes in the form of mosses, lichens and algae. The
\end{abstract}

paper shows the need for the interaction of all interdisciplinary contexts that lead to quality reconstruction and renovation interventions, the aim of which is to extend the life of a panel residential housing by at least another twenty years.

Keywords Buildings, Energy, Facades, Environment, Biodegradation, Microorganism, Algae, Legislation

\section{Introduction}

In its Housing and Health Guidelines, the World Health Organization (WHO) emphasizes, among other aspects, the importance of healthy housing conditions and healthy living indoor and outdoor [1]. A number of multidisciplinary factors influence the quality of housing. Among these are factors of a scientific, social, environmental, technical and economic nature and clearly factors of construction disciplines including structural architecture along with material and technological solutions. These factors create an interaction of requirements for the overall quality of housing $[2,3]$.

Endeavours of the current construction industry to work towards the requirements of the energy concept and thermal protection of buildings set by the European Union as the energy efficiency target for 2030 and beyond include the use of ETICS (External Technical Insulation Composite Systems) [4-8] applied in building envelopes as part of thermal insulation measures. Application of ETICS is extensive and is evident throughout Europe, especially in 
countries of Eastern Europe, such as the Czech Republic, Poland, Slovakia and the former East Germany; that is, where large-scale construction of blocks of flats using prefabricated apartment building technology took place after the end of the World War II. [9, 10]. A reconstruction of these blocks of flats was required to meet the thermal-technical energy performance requirements and the use of ETICS seemed to be a suitable option in terms of construction, material and technology.

While the fulfilment of the requirements of thermal-technique is beneficial for the society, we encounter at the same time, new problem in this area. These are mainly biodegradation of facades equipped with ETICS. Stricter thermal-technical and energy saving requirements lead to increased thickness of the thermal insulator. In 1970s, they considered thermally insulating envelopes with a thickness between $50 \mathrm{~mm}$ and $80 \mathrm{~mm}$ adequate. However, that has changed to meet the current requirements. Thermally insulating material applied on the standard external prefabricated panel wall thickness between $270 \mathrm{~mm}$ and $300 \mathrm{~mm}$ must have a thickness between $180 \mathrm{~mm}$ and $200 \mathrm{~mm}$ [11].

The physical nature of the heat transfer of the additionally insulated façades predicts the condensation zone in the ETICS at the outer face, which makes the façades cooler on the surface. The natural infiltration of the insulated perimeter wall is lost; the possibility of starting the biodegradation process becomes favorable. The issue is documented in a case study for the city of Ostrava in the Czech Republic.

\section{Climatic Zones of Czech Republic}

The climate in the Czech Republic is characterized by mutual penetrations and mixing of oceanic and continental influences. The climate is characterized by westerly currents with a predominance of westerly winds, intense cyclonic activity and precipitation. The maritime influence is particularly evident in the Czech Republic; continental climate influences are increasing in Moravia and Silesia.

The climate in the Czech Republic is influenced by altitude and its relief. Of the total area of the state territory, $52,817 \mathrm{~km}^{2}$ lie at an altitude of up to $500 \mathrm{~m}$ (that is $66.97 \%$ ), $25,222 \mathrm{~km}^{2}$ at an altitude of 500 to $1,000 \mathrm{~m}$ (that is $31.98 \%$ ) and only $827 \mathrm{~km}^{2}$ at an altitude of over $1000 \mathrm{~m}$ (that is $1.05 \%$ ). The average altitude of the Czech Republic is 430 $\mathrm{m}$; relief is shown in Figure 1 [12].

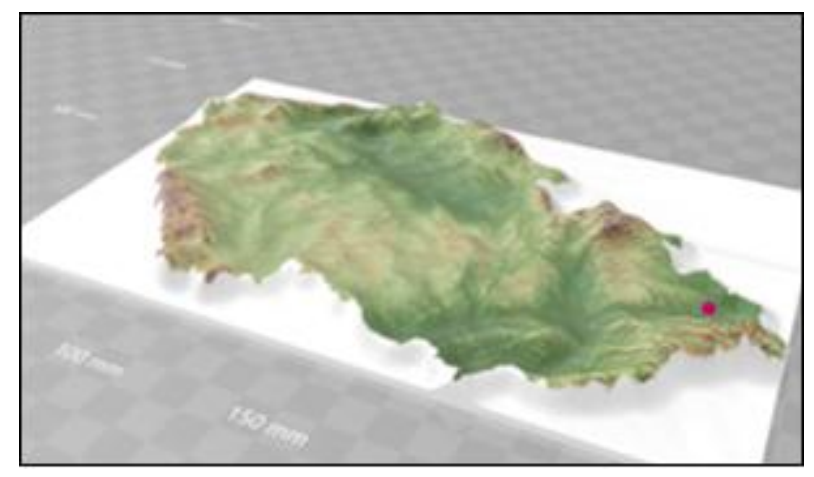

Figure 1. Relief of the Czech Republic and point and the point (red colour) of the city of Ostrava [14]

From the point of view of thermal engineering and the assessment of building structures, temperatures, air humidity, wind direction and speed, and the time and intensity of solar radiation are important.

The basic design values of the parameters of the outdoor environment in the Czech Republic in accordance with Code CSN 730540 include:

- Design outdoor air temperature in winter.

- Design outdoor air temperature in summer.

- Relative humidity of the outside air.

Meteorological data can be used for the reference climatic year, which are used for year-round dynamic or mathematical modeling of energy, temperature, humidity and technical conditions of buildings equipped with technical equipment to ensure the required parameters of the indoor environment. The Ashrae database for the Czech Republic contains detailed data for the city of Prague and Ostrava [13], (2.1). The course of hourly average outdoor air temperatures for Ostrava is shown in Figure 2.

Design outdoor air temperature $\theta \mathrm{e}$ in winter according to the relation:

$$
\theta_{e}=\theta_{e, 100}+\Delta \theta_{e}
$$

Where:

$\theta_{\mathrm{e}, 100}=$ basic design temperature of outdoor air in the temperature region of the Czech Republic (see Table 1), determined for an altitude of $1000 \mathrm{~m}$ above sea level in $\left({ }^{\circ} \mathrm{C}\right)$

$\Delta \theta_{e}=$ altitude gradient in $(\mathrm{K})$ for the given temperature range, which for the site of the building with altitude $\mathrm{h}$, from the relation $\Delta \theta_{e}=\Delta \theta_{e, 0} . \Delta h / 100$, where $\Delta \theta_{e, 0}$ is the basic temperature gradient for a given temperature range $\Delta h=\mathrm{h}-100$

Table 1. Temperature regions of the Czech Republic

\begin{tabular}{|c|c|c|c|}
\hline Temperature range & $\begin{array}{c}\text { Average altitude in the } \\
\text { temperature range } h_{\mathrm{m}} \text { above } \\
\text { sea level }\end{array}$ & $\begin{array}{c}\text { Basic design outdoor air } \\
\text { temperature for an altitude of } 100 \\
\mathrm{~m} \text { above sea level }\left({ }^{\circ} \mathrm{C}\right)\end{array}$ & $\begin{array}{c}\text { Basic temperature gradient above } \\
100 \mathrm{~m} \text { above sea level } \Delta \theta_{0}(\mathrm{~K})\end{array}$ \\
\hline 1 & 240 & -12 & -0.5 \\
\hline 2 & 320 & -14 & -0.3 \\
\hline 3 & 540 & -16 & -0.2 \\
\hline 4 & 820 & -18 & -0.2 \\
\hline
\end{tabular}




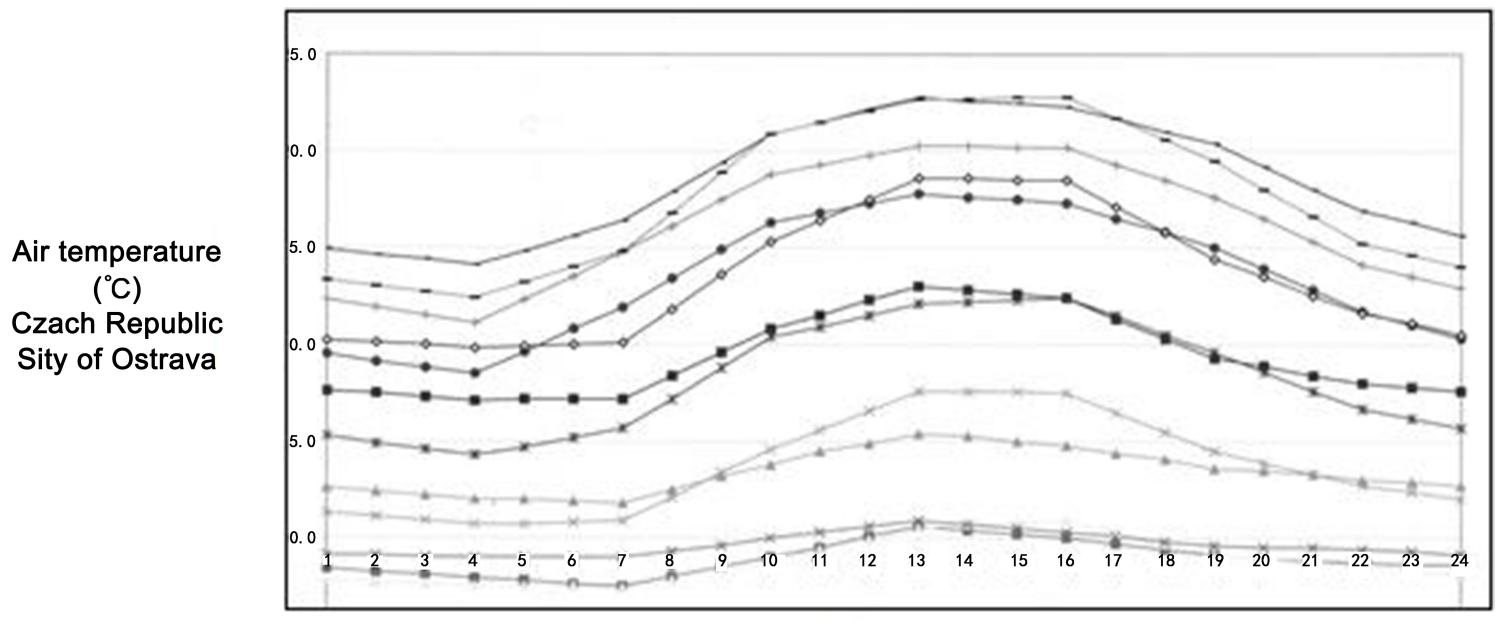

Hourly outdoor air temperature $\left({ }^{\circ} \mathrm{C}\right)$

Figure 2. Hourly average outdoor air temperatures for the city of Ostrava [12]

Design average monthly outdoor air temperatures in the annual course are used to determine the year-round balance of condensation and evaporation of moisture for the building structure $\theta_{e, m m}$; the design values for the Czech Republic, which are evaporated by months, are national climatic data for the calculation of the year-round condensation balance and the heat demand for heating residential buildings. For the temperature range (linked to the case study) the determination of the temperature range is $18.2^{\circ} \mathrm{C}$.

\section{Materials and Methodology}

We have documented the issue of biodegradation of external prefabricated panel walls by monitoring samples of blocks of flats built of these panels, on a case study [15, 16]. The aim of this monitoring was to verify a quality status of ETICS, after five and ten years period of its application on selected block of the external prefabricated panel walls of the flats and document whether it is possible, that biodegradation is formed due to the increasing thickness of the thermally insulating material. This assumption is stated by some professional sources [17-20].

For monitoring purposes, was selected ten blocks of flats built in the 1980s, built of the prefabricated panels, of the total number of prefabricated apartment buildings 124; the built-up area is 50 ha. The blocks of flats were refurbished around 2010 when between th. $50 \mathrm{~mm}$ to $80 \mathrm{~mm}$ and th. $100 \mathrm{~mm}$ and $160 \mathrm{~mm}$ thick ETICS was applied on the external walls constructed of lightweight slag-pumice concrete or silica fume.

Samples were taken in places where has been identified change in the colour of the external plaster, visually obvious, always at a height of $1.5 \mathrm{~m}$ to $1.7 \mathrm{~m}$ above the finished terrain or at window jambs in cases of higher floors.

A total of 10 samples prefabricated apartment buildings were monitored, of which for 1 house 1 sample at the level of $1.5 \mathrm{~m}$ to $1.7 \mathrm{~m}$ from the prepared terrain and 1 sample in the uppermost floor at the window lining.

The monitored blocks of flats were 6 to 8 floors tall and located within an urbanized area of a housing estate set in standard vegetation (deciduous and coniferous trees arranged as a park).

\subsection{Material}

The basic material for the evaluation is as follows:

- Location - urbanized residential area, Ostrava, CZ: area of $50 \mathrm{ha}$, the area is abundantly represented by mature vegetation, without proximity to the water surface (natural or artificial).

- Prefabricated apartment buildings (in a selected number of 10 from 124 total, in a selected number of 10 from 71), reference prefabricated apartment building.

- Determination of ETICS in thickness between $50 \mathrm{~mm}$ to $80 \mathrm{~mm}$ and $100 \mathrm{~mm}$ to $160 \mathrm{~mm}$ according to available project documentation, or determination of the thickness of ETICS by measuring it at the lining of window openings.

- Verification of whether prophylactic recommended care for ETICS has been carried out on the blocks of flats (this is a verification of the maintenance system that ensures the cleaning of the façade at the recommended interval of five years (characteristics descriptively).

- Determination of whether they coated the external surface of the ETICS with a photocatalytic coating, according to the maintenance system records (characteristics descriptively).

\subsection{Methods}

Applied methods, procedures and laboratory analyzes 
are as follows:

- Theoretical basis for the life of microorganisms in ETICS.

- Diagnostics - visual methods; sampling for laboratory analysis.

- Defining structural and physical contexts and perimeter wall modeling using software support [21].

- Sampling for laboratory analysis; laboratory analysis of samples taken, and detection of biodegradation and determination of the genus of microorganisms [22].

The approach to the researched issue of the selected material is shown in Figure 3. The reference panel apartment building can be seen in Figure $4 \mathrm{~b}$ ) and rated area in Figure 4 a). Methodological approaches are based on the state of knowledge of the issue [23, 24].

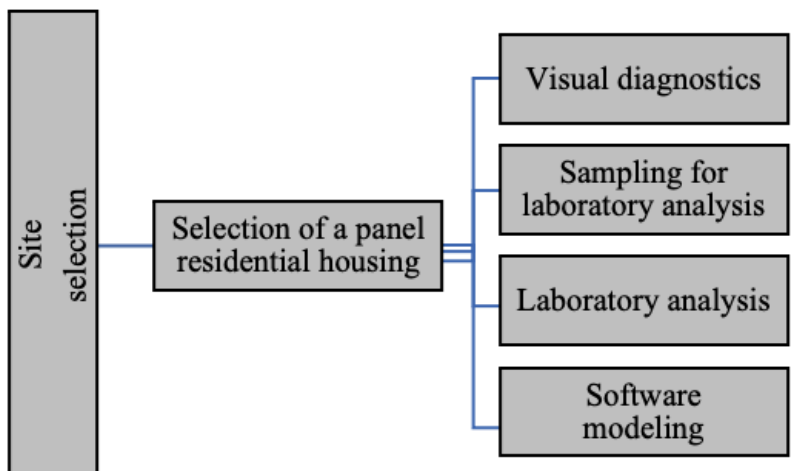

Figure 3. Flow chart of methodological approach

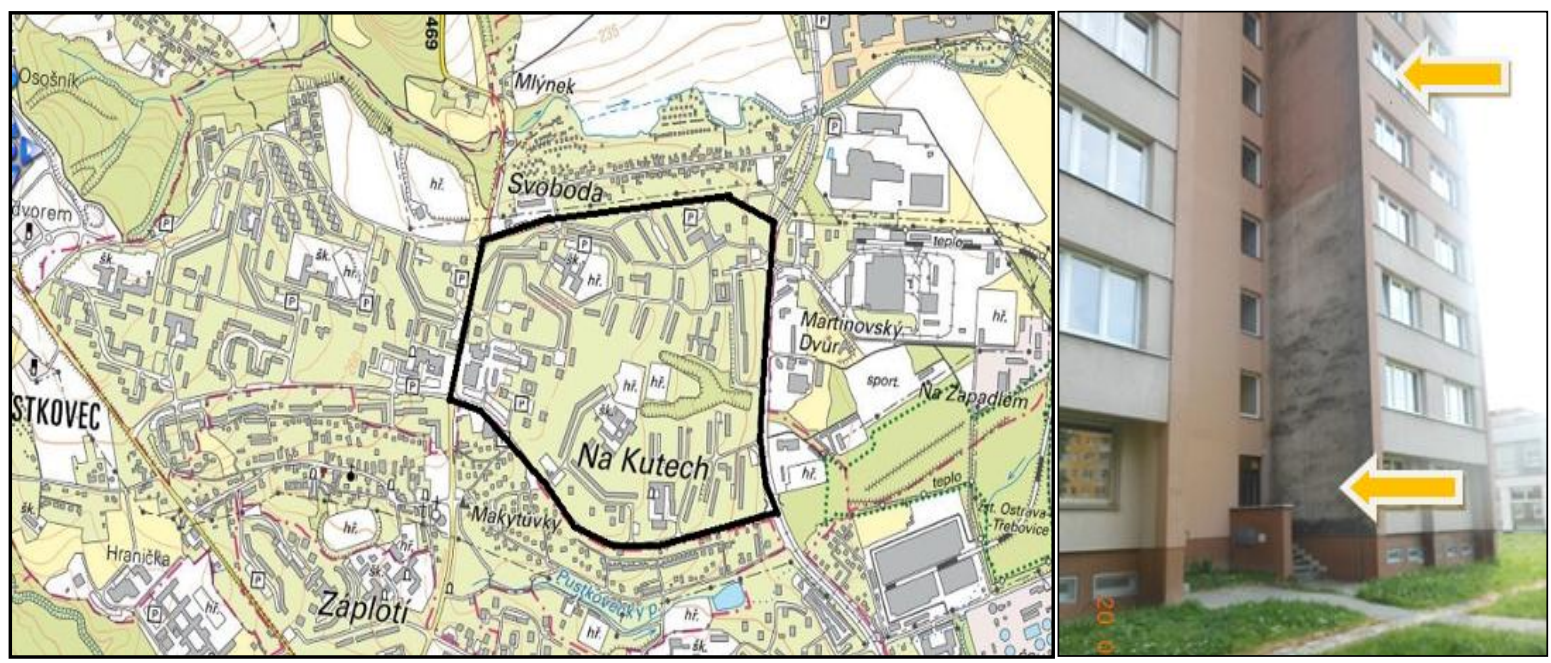

a)

b)

Perimeter cladding - slag concrete th. $270 \mathrm{~mm}$; Heat transfer coefficient before thermal insulation ETICS $\mathrm{U}_{\mathrm{N}}: 1.91 \mathrm{~W} /\left(\mathrm{m}^{2} . \mathrm{K}\right)$; Heat transfer coefficient after thermal insulation ETICS $\mathrm{U}_{\mathrm{N}}$ th. $160 \mathrm{~mm}: 0.22 \mathrm{~W} /\left(\mathrm{m}^{2} . \mathrm{K}\right)$.

Figure 4. Area and reference of prefabricated apartment buildings and basic characteristics (a) Built-up area for monitoring; (b) Reference prefabricated apartment building. 


\subsubsection{Theoretical basis for the life of microorganisms in ETICS}

Process bacteria, fungi and algae are commonly found in the environment and under certain conditions can grow on the facades of blocks of flats.

The theoretical basis of formation of biodegradation is derived from the fact that prerequisites for the microorganisms to live include humidity, nutrients, temperature, light, oxygen as well as a favourable $\mathrm{pH}$ value.

Sources state that microorganisms that occur on the surfaces of thermally insulated facades are also found in the interiors of prefabricated blocks of flats, due to e.g. inappropriate mode of ventilation, that the migration of microorganisms is a natural phenomenon in a given environment and that most of the microorganisms are transmitted by air [25, 26]. Most microorganisms are dependent on the presence of water, which promotes their expansion in moist places by surface colonization.

As a source of nutrition for microorganisms, algae and fungi are needed in particular: $\mathrm{CO}_{2}$, trace elements, water, organically bound carbon, nitrogen source. Favorable conditions for growth are created by air humidity, condensation, ev. PM10 dust particles. Both mushrooms and algae need temperature and light to live. For algae, the temperature is favorable from $-10^{\circ} \mathrm{C}$ to $+70^{\circ} \mathrm{C}$ and algae need light. For mushrooms, the temperature is favorable from about $0^{\circ} \mathrm{C}$ to $50^{\circ} \mathrm{C}$ and the mushrooms do not require light. Research shows that the most common fungi on facades are fungi of the genera Alternaria, Cladosporium, which are able to grow on facades even at low temperatures [27]. Other activators of the growth of microorganisms include regional areas where atmospheric precipitation or fog is frequent. There is a very high probability of biotic attack on facades. Similarly, smog and chemical air pollution increase the likelihood of microorganisms attacking the facade.

\subsubsection{Diagnostics - visual methods, sampling for} laboratory analysis

Visual monitoring included:

- Façade: visually visible clean, undamaged façade plaster.

- Facade: change of color of the facade plaster in local places with an area of $0.5 \mathrm{~m}^{2}$.

- Façade: color change of façade plaster in an area larger than $0.5 \mathrm{~m}^{2}$.

Sampling from visually degraded sites by biodegradation for laboratory analysis can be seen in Table 2. An overview of ETICS thickness for monitored houses:

- ETICS th. $50 \mathrm{~mm}$

- ETICS th. $60 \mathrm{~mm}$

- ETICS th. $80 \mathrm{~mm}$

- ETICS th. $100 \mathrm{~mm}$

- ETICS th. $120 \mathrm{~mm}$

- ETICS th. $160 \mathrm{~mm}$

- ETICS th. $180 \mathrm{~mm}$

\section{(for documentation of the issue)}

The localized sampling sites had a larger area $>0.5 \mathrm{~m}^{2}$ (visually).

Table 2. Sampling from degraded sites

\begin{tabular}{|c|c|c|c|}
\hline $\begin{array}{c}\text { Panel } \\
\text { residential } \\
\text { housing }\end{array}$ & $\begin{array}{c}\text { Height } 1.5-1.7 \mathrm{~m} \\
\text { above the } \\
\text { prepared terrain }\end{array}$ & $\begin{array}{c}\text { Window lining } \\
\text { on the 6th floor } \\
\text { or 8 floors }\end{array}$ & Total \\
\hline $1-10$ & $\begin{array}{c}\text { ten samples in } \\
\text { total }\end{array}$ & $\begin{array}{c}\text { ten samples in } \\
\text { total }\end{array}$ & $\begin{array}{c}20 \text { samples } \\
\text { fol laboratory } \\
\text { analysis }\end{array}$ \\
\hline
\end{tabular}

3.2.3. Defining structural and physical contexts and perimeter wall modeling using software support

It follows from the generally known building-physical contexts that external plasters of ETICS, which most often are acrylic, silicate, and silicone, are subjected to more stress by moisture than plasters of single-layer finishes. Water from the surface of external plasters applied on a base is not provided with ETICS migrates by capillary conductivity towards a dry surface, and thus the occurrence of water emulsion is significantly shorter compared to facades provided with ETICS. In contrast, the polystyrene used in ETICS is insoluble in water and has a closed microscopic structure, whereby closed pores in its structure absorb almost no water and water is concentrated on the surface. The surface layer of buildings with ETICS stays cold, especially in autumn and spring, and it is not warmed by the heat that escapes from the interior of the buildings through the walls. As is the case with buildings without ETICS, the single plaster layer of which warms up. Conversely, the greater the thickness of the ETICS insulation, the greater the theoretical prediction of moisture on the outer surface and the impact of biodegradation on the facade.

ETICS external thermal insulation keeps the interior warm, whereas its external plaster cool down is intense, especially on clear nights, when the ETICS surface temperature drops faster than the ambient air temperature. If the temperature drops below the dew point, moisture condenses on the cold surface of the facade. Condensate and moisture form under cold conditions and stay on the surface of the facade, particularly on the northern side of the building or on sides that are more shaded. The conditions for the growth of microorganisms thus become favourable, as the microorganisms have a sufficient supply of nutrients.

Figure 5 shows the course of relative humidity at the gable wall of a prefabricated block of flats with the extruded polystyrene thermal insulator thickness between $110 \mathrm{~mm}$ to $160 \mathrm{~mm}$.

Moisture propagates from the original single-layer panel wall construction (A), on a material base of slag-pumice concrete or silica fume towards a part of the ETICS thermal insulation (B to D). Moisture is then established on the surface of the external plaster and a suitable substrate because the growth of microorganisms is formed.

The relationship between the thermal insulation 
thickness and the temperature of the facade surface under standard model conditions is given by the parameters $\theta \mathrm{e}=$ $-15^{\circ} \mathrm{C}, \theta \mathrm{i}=21^{\circ} \mathrm{C}$. The surface temperature of the façade before the application of additional ETICS thermal insulation is $\theta \mathrm{se},(0)=-13.0^{\circ} \mathrm{C}$. After the application of thermal insulation with a thickness of only $20 \mathrm{~mm}$, there is a significant drop in temperature of $0.7^{\circ} \mathrm{C}$. After applying ETICS with a thickness of $200 \mathrm{~mm}$, the temperature is reduced to, $(200)=-14.7^{\circ} \mathrm{C}$, i.e. a difference of $1.7^{\circ} \mathrm{C}$.

Part (B) and (C) show the increasing thickness of the insulation and the condensation zone. It is shown in which area of the perimeter wall the relative humidity of the wall is directed, which at the thickness of insulation meets the conditions according to standard requirements $\mathrm{U}_{\mathrm{N}}=0.25$ $\mathrm{W} /\left(\mathrm{m}^{2} . \mathrm{K}\right)$, but on the other hand creates a moist substrate suitable for biodegradation.

In accordance with the requirements of Code ČSN 73 0540 and ČSN ISO 6946 (see Table 3), the heat transfer coefficient $\mathrm{U}_{\mathrm{N}}$ at an insulator thickness of $180 \mathrm{~mm}$ complies with "(3.1)", "(3.2)". The construction of heated buildings must meet this condition in rooms with a design relative humidity of indoor air $\varphi_{i} \leq 60 \%$. In the case of building structures in areas with a design relative humidity of indoor air $\varphi>60 \%$ the risks of mold growth must be ruled out in the winter.

$$
\mathrm{U} \leq \mathrm{U}_{\mathrm{N}}
$$

$$
\mathrm{U}=0.20 \mathrm{~W} /\left(\mathrm{m}^{2} . \mathrm{K}\right)<\mathrm{U}_{\mathrm{N}}=0.30 \mathrm{~W} /\left(\mathrm{m}^{2} . \mathrm{K}\right)
$$

Table 3. Development of heat transfer coefficient.

\begin{tabular}{|c|c|c|c|}
\hline $\begin{array}{c}\text { Perimeter } \\
\text { wall } \\
\text { thickness } \\
(\mathrm{mm})\end{array}$ & $\begin{array}{c}\text { Perimeter } \\
\text { ETICS } \\
(\mathrm{mm})\end{array}$ & $\begin{array}{c}\text { Coefficient of } \\
\text { heat transfer of } \\
\text { the structure } \\
\mathrm{U} \mathrm{W} /\left(\mathrm{m}^{2} . \mathrm{K}\right)\end{array}$ & $\begin{array}{c}\text { Recommended } \\
\text { value } \\
\mathrm{U}_{\mathrm{N}} \\
\mathrm{W} /\left(\mathrm{m}^{2} . \mathrm{K}\right)\end{array}$ \\
\hline 270 & 0 & 1.91 & $0.30^{1} / 0.25^{2}$ \\
\hline 270 & 150 & 0.23 & 0.25 \\
\hline 270 & 180 & 0.20 & 0.25 \\
\hline 270 & 200 & 0.18 & 0.25 \\
\hline
\end{tabular}

${ }^{1}$ Required value (Code ČSN 73 0540, for the CZ).

${ }^{2}$ Recommended value (Code ČSN 730540 for the CZ).

The insulation thickness of 160 to $180 \mathrm{~mm}$ is currently the most frequently applied thickness on the perimeter cladding of prefabricated apartment buildings (to ensure standard requirements).

The distribution of water vapor pressures at a typical location of the structure is documented in Figure 6 Part (a), which shows: the circumferential structure of th. $270 \mathrm{~mm}$ without ETICS, in composition: internal lime-cement plaster, slag-cement-concrete perimeter wall, external core plaster; part (b) shows the circumferential construction of th. $270 \mathrm{~mm}$ with ETICS insulation in th. $180 \mathrm{~mm}$ at th. perimeter walls $270 \mathrm{~mm}$ made of slag-cement concrete, in composition: internal lime-cement plaster, slag-cement-concrete perimeter wall, ETICS insulator, external core plaster.

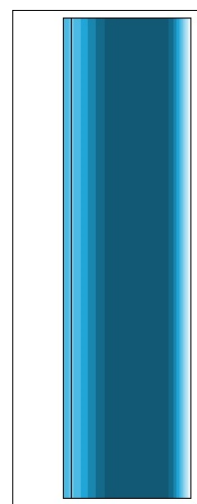

A.

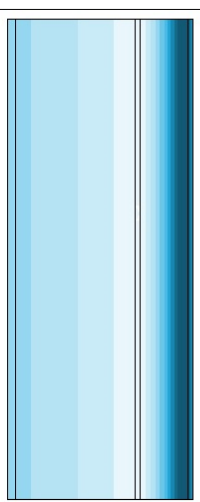

B.

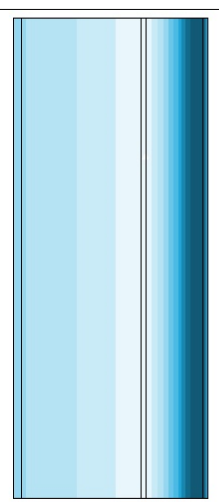

C.

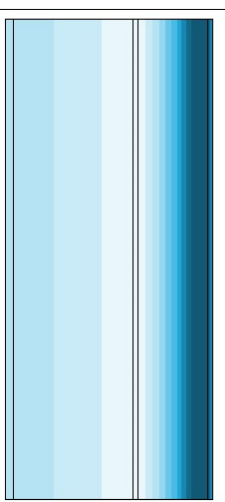

D.
Relative humidity (\%)

$40 \ldots 46$

$46 \ldots 52$

$52 \ldots 58$

$58 \ldots 64$

$64 \ldots 70$

$70 \ldots 76$

$76 \ldots 82$

$82 \ldots 88$

$88 \ldots 94$

$94 \ldots 100$

Figure 5. Course of relative humidity of the gable wall: (A) Original wall without thermal insulation, (B) Wall with 110 mm thick thermal insulation; (C) Wall with $130 \mathrm{~mm}$ thick thermal insulation; (D) Wall with $160 \mathrm{~mm}$ thick thermal insulation. Modeling in Heat software support [21]. 


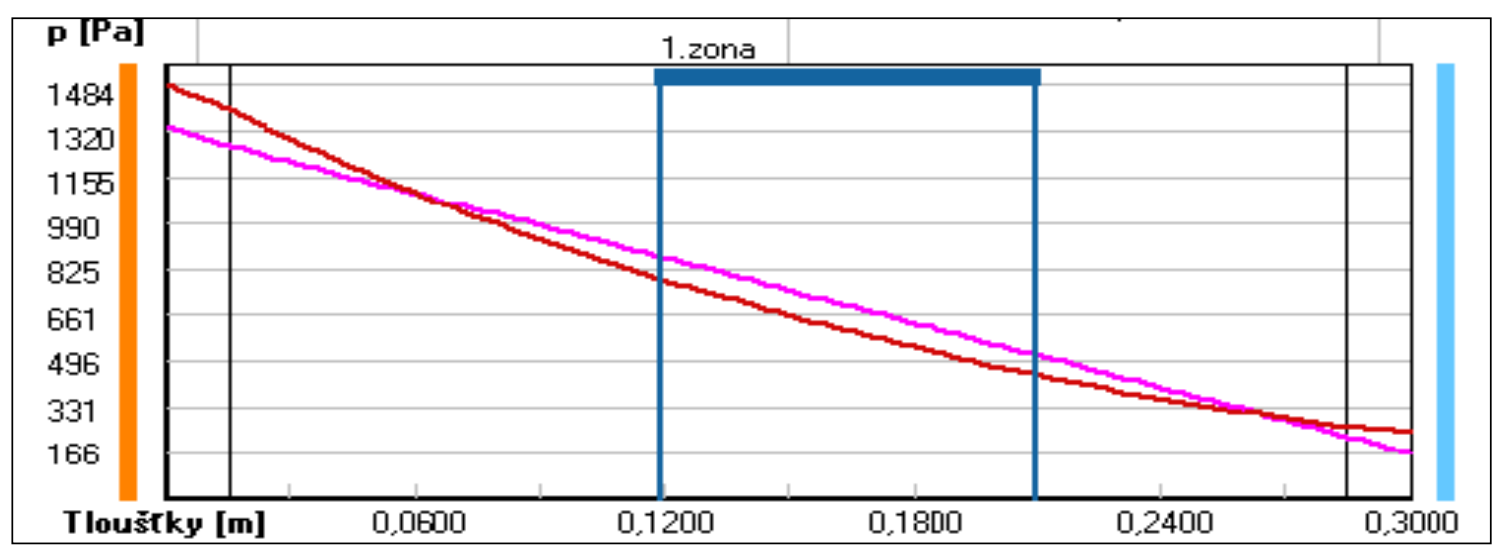

a)

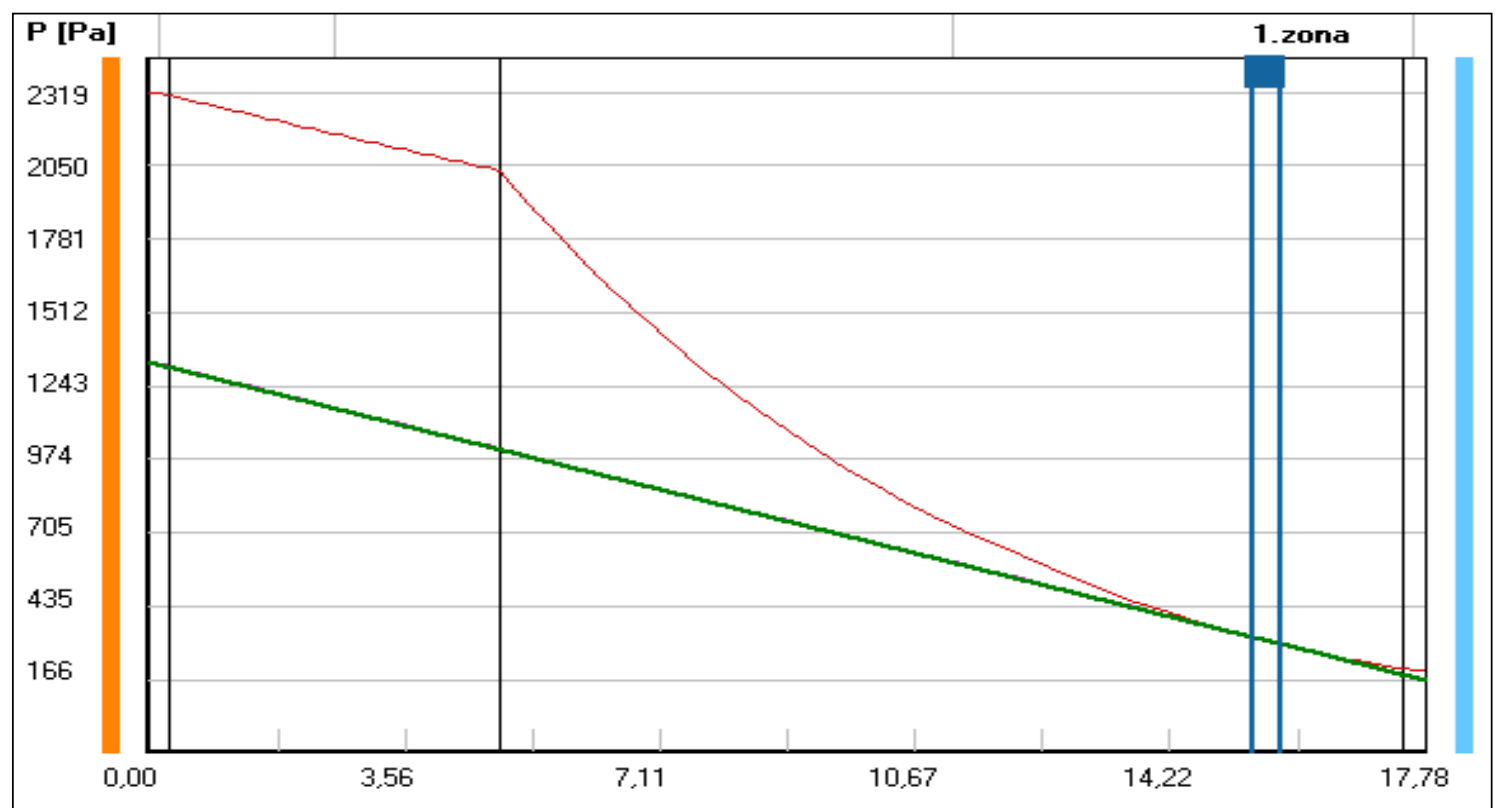

b)

Figure 6. Heat transfer coefficient at the perimeter wall: (a) Perimeter wall th. $270 \mathrm{~mm}$ made of slag-cement concrete without ETICS, (b) Perimeter wall th. $270 \mathrm{~mm}$ made of slag-cement concrete with ETICS in th. $180 \mathrm{~mm}$. Modeling in Heat software support [21].

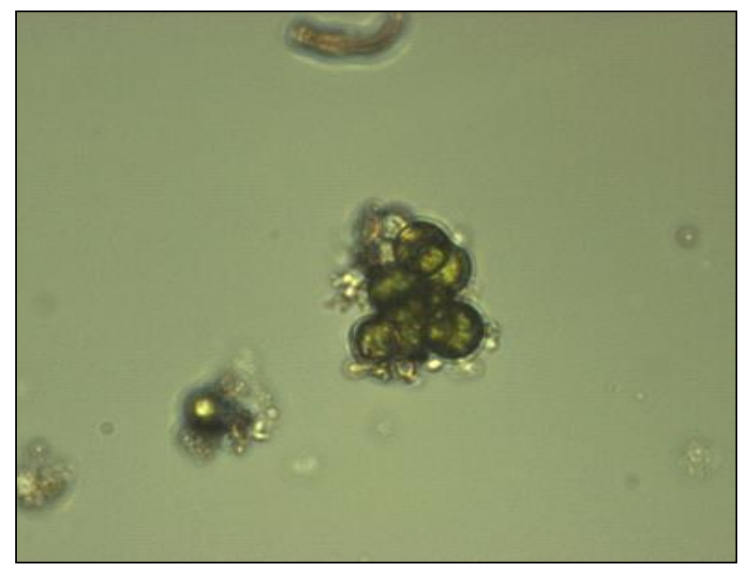

a)

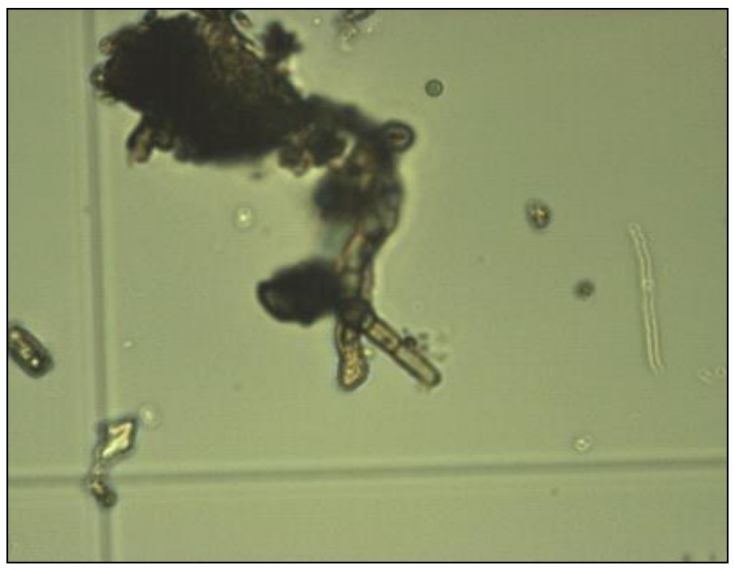

b)

Figure 7. Photomicrographs of the sample extract at $400 \mathrm{x}$ magnification: (a) Algae Chlorophyceae, (b) Fungi Dothideomycetes [22]. 


\subsubsection{Sampling for laboratory analysis; laboratory analysis} of samplex taken and detection of biodegradation and determination of the genus of microorganism

The laboratory analysis of the plaster samples taken showed that the most frequently represented in them were green terastic algae Chlorophyceae and fungi of the genus Dothideomycetes, as is seen in Figure 7 a) and b). Abstractions from highly degraded surfaces by biodegradation can be seen in Figure 8.

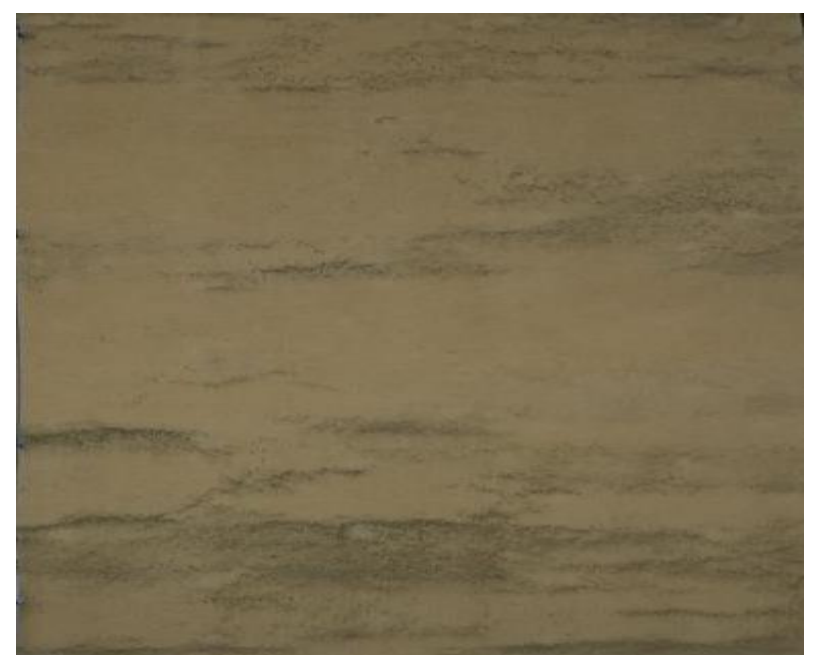

Figure 8. Exterior facade of a prefabricated panel type block of flats degraded by microorganisms [15]

\section{Results and Discussion}

The following findings emerge from the performed surveys, monitoring, software modeling and laboratory analysis of microorganisms:

- Out of the total number of 124 prefabricated apartment buildings, 71 buildings were monitored (i.e. $57.26 \%$ ), for analyzing 10 prefabricated apartment buildings out of the number of 71 (i.e. 14.10\%).

- No monitored house has been photocatalytically coated, and prophylactic care has not been applied to the façade since the ETICS application.

- A total of 20 samples were taken for laboratory analysis in 10 prefabricated apartment buildings.

- In all samples taken (ie 100\%) the presence of microorganisms was detected by laboratory analysis (the laboratory analysis of the plaster samples taken showed that the most frequently represented in them were green terastic algae Chlorophyceae and fungi of the genus Dothideomycetes. This is confirmed by expert opinions (Chapter 3, especially algae Chlorophyceae [17-20]).

- The dependence of microorganisms on the increasing thickness of ETICS thermal insulation has not been proven. All prefab residential housing were affected by biodegradation. The biodegradation stands were larger in area at the perimeter walls of the prefab residential housing, which were oriented in the north and northwest directions.

It turns out that the environmental context is obvious. The viability of microorganisms is extensive. The cold surface of ETICS creates favorable conditions for the colonization of the facade by microorganisms. If regular care of the facade is not started, preferably at five-year intervals, the probability of occurrence is almost $100 \%$ from an insulator thickness of $100 \mathrm{~mm}$ and more.

\section{Conclusions}

This study can contribute to the understanding of the broader links between increasing thermal engineering and environmental requirements.

Although the reference sample of external plaster facades applied with ETICS in prefabricated panel type blocks of flats is represented by a small number of evaluated buildings (ten buildings), it can be stated that facades that had greater insulation thicknesses and were primarily oriented to the north are much more affected by biodegradation than the sunlit facades and facades where the thickness of the insulation is smaller. This can be understood as a natural phenomenon; microorganisms in the moist ETICS have a sufficient supply of nutrients and suitable living conditions and they can form a surface colonization of facades over time.

The analysis of the information obtained from the monitored prefabricated panel type blocks of flats with ETICS applied approximately ten years ago showed that the buildings were not in the prophylactic care system (no cleaning of the facade with pressurized water or other photocatalytic coatings was performed). It is definitely wrong to believe that the facade of the building finished with ETICS is maintenance-free. On the contrary, experience shows that these buildings need to be increased and be given systematic care and maintenance, and that the thermally insulated facades should be cared regularly and preferably within every five years.

In terms of energy saving and the EU strategy for the use of ETICS in construction, there are clear positives. ETICS is a comprehensive certified system, it is environmentally friendly, it contributes, among other things, to the aesthetic improvement of the façade; and acording to the EU strategy it has a positive effect on the construction market and supports the growth of job opportunities.

We must also take into account that the prefabricated apartment buildings in the countries of Eastern Europe is relatively extensive and the approach to this form of housing is completely different from that in Western European countries. Western states withdrew from the form of prefabricated panel housing construction in the 1970s while this construction trend in Eastern European countries continued until the 1990s. While Western countries associate this type of housing development with 
socially weaker groups, the countries of the Eastern Europe consider it currently as a good quality housing for a large part of population.

It turns out that the biodegradation of external walls finished with ETICS is characterized as a modern failure in the construction industry. Biodegradation of external walls significantly worsens the aesthetic appearance of the facades of prefabricated panel type buildings and contributes to the degradation of the surface structure of plasters. From a long-term point of view, it cannot be ruled out that biodegradation processes may cause the formation of micro-cracks in the finishing plaster layer.

No side effects in the form of biodegradation of ETICS applied to external walls were found at the end of the last century. The cause of this defect can be directed to the field of building physics, materials science and environmental matters. There are strong and interdependent links between these fields. Therefore, it is necessary to pay due attention to the recommended remedial intervention, especially at the stage of design. It is always necessary to assess the complexity of interactions of the "building-environment". Deepening the knowledge of the building-physical phenomena as well as of the constructional and environmental connectedness will then markedly contribute to the improved quality of buildings.

\section{Acknowledgements}

The work was subsidised by the institutional development for 2019 and 2020 dedicated for VSB-Technical University of Ostrava by the Ministry of Education, Youth and Sports of the Czech Republic.

\section{Conflict of Interest}

The author declare no conflict of interest.

\section{REFERENCES}

[1] Housing-Health Impacts. Online available from https://www.who.int/housing.

[2] I. Juhaz-Šenitková, M. Kraus, P. Nováková. Buildings and Environment. Vol.1, pp. 9-16, 2018.

[3] D. Kubečková, M. Kraus, I. Juhaz-Šenitková, M. Vrbová. The indoor Microclimate of prefabricated buildings for housing interaction of environmental and construction measures. Sustainability, Vo.12, pp. 9-16, 2020. DOI: $10.3390 /$ su122310119.

[4] Building Code n. 183/2006. Collection of lows of the Czech Republic, 2006.

[5] Recast EPBD. Directive 2010/31/EU of the European Parliament and of the Council of 19.05.2010 on the energy performance of buildings, 2010.

[6] European Commission Directice 2018/844/EU Energy performance of buildings, 2018.

[7] Czech Code 730540 (inc. changes). Thermal protection of buildings-Part 2 Requirements, Prague, 2013.

[8] Czech Code 73 2901. Performance of external insulation composite systems (ETICS), Prague, 2005.

[9] E. Novotná. Post-war housing construction and monument care on the example of Great Britain and Scandinavia. In: Monument care reports, Medias Res. Vol.75, n.4, 2015.

[10] K.E. Zarecor. The Shaping of Socialist Modernity: Living in Czechoslovakia in 1945-1960. In: Academia, 2015.

[11] D. Kubečková, D. Past and Perspectives of Panel Housing Construction. Inaugural lecture. VSB-TU Ostrava, 2010.

[12] J. Vaverka, and col. Building thermal technique and energy of buildings. Publishing Vutium Brno, Vol. 1, 2006.

[13] Database Ashrae, www.ashrae.org (climatic design conditions, wheather data center).

[14] https://www.mk3d-prints.cz/relief-cr-vyskova-mapa.

[15] M. Vrbová. Factors Affecting Microbial Growth on Facades. Diseratiton Work. VSB-Technical University of Ostrava, 2020.

[16]D. Kubečková. Own forensic archive of Civil Engineering and Architecture (2000-2020).

[17] D. Kubečková, D. Structural Design of the Architectonics Details. Speech on Plenary meeting 25.06.2013, Saint Petesburg, Confrence $5^{\text {th }}$ Contemporary Design of the Architectonics Details, 2013.

[18] V. Kučeríková, D. Kubečková, H. Brtošová, H, J. Kukutschová. The Biotic on Frontage. In: Advanced Materials Researcher. Trandtech Publiccations Ltd. Zürich. Vol.1020, pp. 615-620, 2014.

[19] R. Wasserbauer. Biological Degradation on Facades. Publishing: Prague Arch. Vol. 1, 2010.

[20] R. Büchli, P. Raschle. Algae and Fungi on the Facades. Vol. 1, pp. 9-14, 2004.

[21] Software Teplo, Svoboda, Czech Republic.

[22] Evaluation report of microorganisms. Nanotechnology center VSB-TU Ostrava, 2017-2019.

[23] A. Shandilya, M. Hauer, W. Streicher. "Optimization of Thermal Behavior and Energy Efficiency of a Residential House Using Energy Retrofitting in Different Climates," Civil Engineering and Architecture, Vol. 8, No 3, 335-349. DOI: $10.13189 /$ cea.2020.080318.

[24] E. C. Macabutas, A. F. Tongco. "Air Temperature Analysis of a Residential House Using Soliworks Flow Simulation," Civil Engineering and Architecture, Vol. 8, No 5, 792-800. DOI: $10.13189 /$ cea.2020.080506.

[25] R.J. Milacarek, S. Turner, R. Zhang, J. Ahn. J.S. Zhang. Predicting Envelope and Micro Cogeneration Design Conditions for Future Climates. ASHARAE, 2017. Proseedings Paper. 
[26]P. Dang, Z.w. Niu, S. Gab, L. Hou G.M. Zhang. Critical Factors Influencing the Sustainable Construction Capabality in Prefabrication Chines Construction Enterprises. Sustainability. Vol.12. Is.21.
[27] A. Poulíčková. Basics of Ecology of Cyanobacteria and Algae. Publishing Palacky University in Olomouc. Vol 1, 21-33, 2011. 